\title{
An Intersectionality Analysis of Gender, Indigeneity, and Food Insecurity among Ultrapoor Garo Women in Bangladesh
}

REVISED REFERENCES, 04/13/2016

\begin{abstract}
Across a number of indicators, Indigenous women worldwide experience poorer health and less access to resources and services than either non-Indigenous women or Indigenous men. This paper is specifically concerned with Indigenous women's experiences of food insecurity, a key determinant of health. We analyse the links between gender, indigeneity, and food insecurity among a small group of ultrapoor Indigenous Garo women in Bangladesh. We demonstrate how the politics of indigeneity, both its erasure by the state and its place in the Indigenous rights movement, intersect with gender to shape the experiences of food insecurity among ultrapoor rural Garo women. We identify how indigeneity intersects with cultural marginalization and political violence in experiences of food insecurity and highlight the unique challenges Garo women face in relation to accessing culturally appropriate and sufficient food. Ultrapoor Garo women are in need of poverty alleviation attention from both Indigenous organizations, who market their cultural capital, as well as governmental and non-governmental aid and development programs that offer such assistance to vulnerable Bengali women.
\end{abstract}

\section{Keywords}

Food insecurity; Indigenous women; Garo; Bangladesh; gender; Indigeneity

\section{Authors}

Jenny Munro drafted the article and supported data analysis. Barbara Parker assisted in drafting the article and conducted the formative analyses of the data. Lynn McIntyre oversaw all aspects of the study including data collection, analysis, and manuscript drafting.

\section{Acknowledgements}

We are indebted to Sanjeeb Drong, General Secretary of the Bangladesh Indigenous Peoples' Forum. We also thank Tahera Yasmin, Porag Ritchil, and the Garo women. Funding for this study was provided by McIntyre's CIHR Chair in Gender, Sex and Health, and a CIHR Global Health and Knowledge Exchange Dissemination Grant. 


\section{Introduction}

It is increasingly recognized that Indigenous populations may experience food insecurity differently than non-Indigenous peoples do. Food insecurity is defined as "limited or uncertain availability of nutritionally adequate and safe foods or limited or uncertain ability to acquire acceptable foods in socially acceptable ways" (Hamilton et al., 1997, p. 5). Power (2008) has argued, "Given the centrality of traditional food practices to cultural health and survival ... cultural food security is an additional level of food security beyond individual, household and community levels" (p. 95). From the standpoint of cultural food security, an aspect of food sovereignty, the right to food is dependent on the right to produce food (Wittman, Desmarais, \& Wiebe, 2011; Patel, Balakrishnan, \& Narayan, 2007), which has significant implications for Indigenous women. Along with Shiva (2000) and Barndt (2008), Desmarais (2003) argues that Indigenous women must have "greater access over land, seeds, water, credit and markets" (p. 141), as "connections to the land" and "access to resources", are imperative for Indigenous food security (Kuhnlein, Erasmus, \& Spigelski, 2009, p. 41).

Despite this recognition, the broader political conditions under which Indigenous populations may access or be excluded from food security are typically underexplored in the literature. Some analyses of food insecurity among Indigenous populations appear to minimize or overlook the contexts of state-Indigenous relations, colonization, settlement or land alienation, marginalization, cultural trauma, and discrimination that are typically seen as essential for understanding contemporary challenges facing Indigenous peoples (Atkinson, 2002; Cannon \& Sunseri, 2011). Devendra \& Chantalakhana (2002), for example, examined food insecurity in Asia with no mention of cultural dislocation, forced assimilation, or other aspects of political violence experienced by Indigenous populations. In contrast, Chilton and Booth (2007), working with African-American women, have cogently argued that food insecurity is linked to gendered forms of violence and marginalization, including domestic violence, childhood sexual abuse, and lack of access to mental health and other social supports. Hughes and Lawrence (2005) have suggested that family food insecurity in the Pacific islands can be understood as a derivative of colonial contact and exploitation, and consequent loss of culture, land, identity, and sovereignty.

This paper is specifically concerned with Indigenous women's experiences of food insecurity, which is a key determinant of health (Public Health Agency of Canada, 2008). Across a number of indicators, Indigenous women worldwide experience poorer health and less access to resources and services than either non-Indigenous women or Indigenous men (Bourassa, McKay-McNabb, \& Hampton, 2005; Haddad, Mohindra, Siekmans, Màk, \& Narayana, 2012; Orticio, 2006; Price \& Asgary, 2011). Using the concept of a "persistent axis of exclusion," Radcliffe and Pequeño (2010) have argued that Indigenous women's "position at the intersection of gender and ethnicity in a post-colonial context results in a specific form of exclusion from ... economic, political, social and cultural processes as well as specific project interventions by states or nongovernmental actors" (p. 985). This intersectionality lens is useful in examining the concept of food sovereignty because the struggle for food sovereignty "is based on a political analysis that challenges power structures blocking realization of the right to food" (Spieldoch, 2007, p. 12). We apply these insights to an analysis of the links between gender, indigeneity, and food insecurity among a small group of ultrapoor (defined as living on less than US\$1 per day) Indigenous Garo women in Bangladesh. 


\section{Historical Overview of the Garo}

The Garo are an Indigenous people who live in India and Bangladesh. This paper is concerned with the Bangladeshi Garo, a matrilineal lowland agricultural population whose 125,000 members live primarily in Mymensingh District (Figure 1) and have largely converted to Christianity.

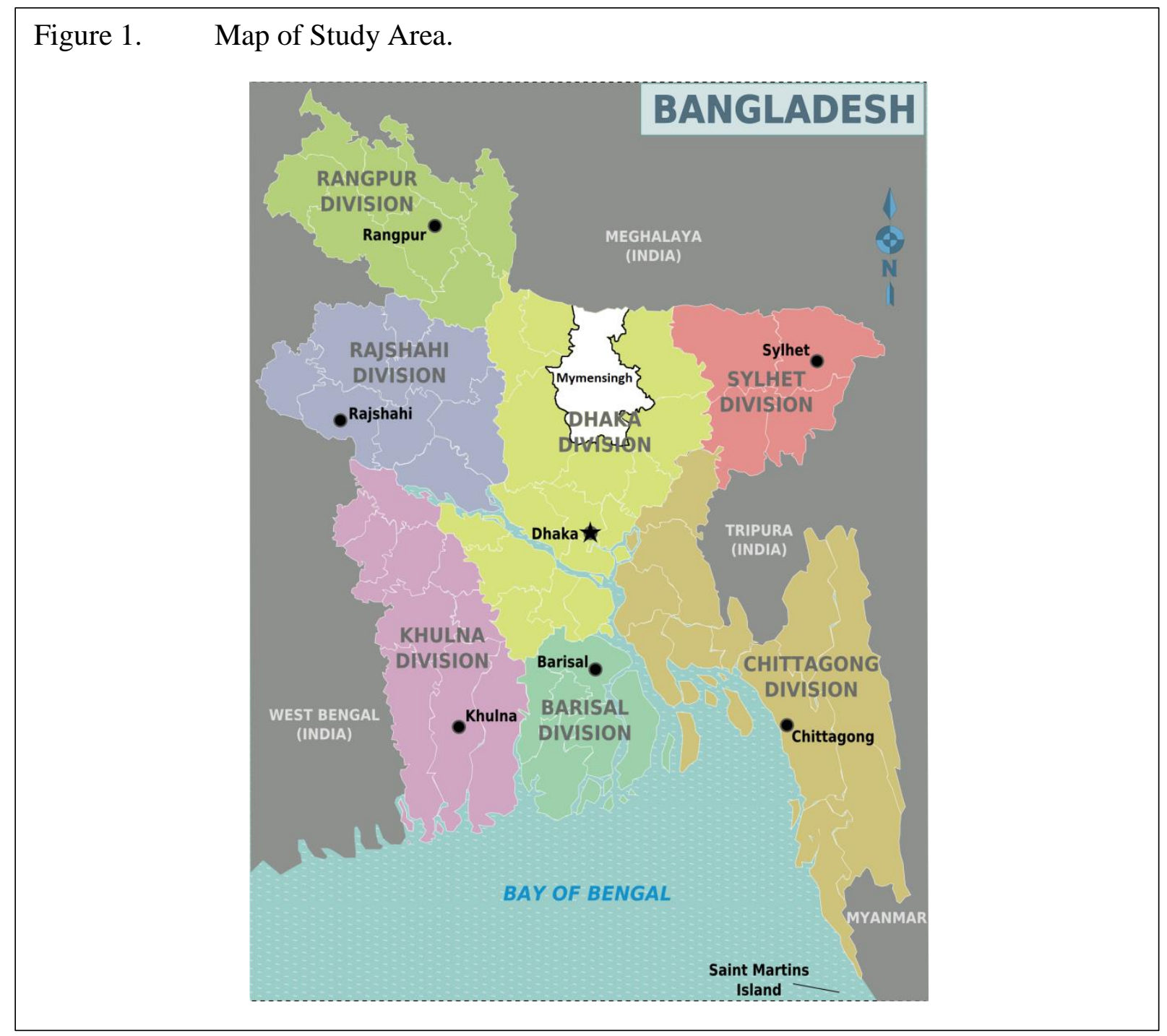

Christian missionaries have been present in the Mymensingh region for over two centuries. In that time they have built schools, provided economic support to individuals in need, and attempted to organize the small village communities around church practices (Bal, 2007a). Beginning in the mid-1960s, the Garo experienced an influx of Bengali Muslims from India and East Pakistan. The newcomers were typically landless migrants or refugees whose presence was supported by the state. Garo populations were threatened and intimidated by illegal settlements, thievery, and suffered physical and sexual violence perpetrated by migrants and their supporters. Many Garo fled the area (Bal, 2007b,). In 1971, what was then West Pakistan invaded East Pakistan, which had declared itself to be the independent state of Bangladesh. Many young Garo men joined the resisters and remained in Mymensingh, uniting with their Bengali counterparts to 
become "freedom fighters" in the battle against the Pakistani army (Uddin, 2008), commonly referred to as the Bangladesh liberation war. Others, particularly women and children, fled again to refugee camps across the Indian border. After a brief bitter war, the Garo who had fled returned to find their homes either destroyed or illegally occupied by Bengalis who had moved north on the promise of land. Although the newly formed Bangladesh government regarded the Garo as ethnically and culturally different from the Muslim Bengali, they did not accord the Garo any rights or special consideration based on their differences. Rather, government policy was shaped to position all citizens, regardless of ethnicity or indigeneity, as Bangladeshi (Bal, 2007a; 2007b). In 1975, Kader Siddiqui, a hero of the 1971 Bangladesh liberation war, recruited Garo men to carry out attacks on the government of the day. Garo participation in these attacks amplified already unfavourable relations with the state. Today, Bengali migrants continue to occupy Garo land and are supported by the Bangladesh government, which promotes Bengali culture, education, language, and the Islamic religion to the exclusion of minority cultures (Das \& Islam, 2005; Bal, 2007b; Uddin, 2008).

Despite a history of dispossession and marginalization, within Bangladesh the Garo are typically viewed as a strong, even upwardly mobile, ethnic minority who have had access to education and jobs that other minorities lack, and who hold prominent roles in the national Indigenous Peoples' movement (Geharz, 2010; see also Bal, 2007a; 2007b). However, it is unclear to what extent these achievements can be applied to the majority of Garo men and women who remain village-based, or even urban Garo women who commonly work as maids in expatriate homes or as beauticians.

Rural Garo women are uniquely positioned with regard to state practices of marginalization and Indigenous political resistance. An Indigenous rights movement has emerged that argues for legal protections and provisions for all Indigenous minorities in Bangladesh. The political movement's overwhelming concern is formal government recognition of indigeneity and implementation of legal strategies to protect cultural identity, language survival, and land ownership (Uddin, 2008). Because the Bangladeshi state rejects the notion of special rights for Indigenous Peoples living within its borders, non-government organizations have attempted to broach the marginalization of minorities by raising awareness of civil rights and placing "emphasis on Indigenous tradition and culture" (Geharz, 2010, p. 9). Indigenous women have become public symbols of Garo culture in the political movement, as Garo community leaders encourage "women to wear ethnic dress and to observe local customs with regard to food preparation, cultivation methods, and handicrafts" (Geharz, 2010, p. 9).

This paper uses an intersectionality analysis to explore how the politics of gender and indigeneity affect the situation of rural Garo women through the lens of food insecurity. Intersectionality is a theoretically based approach that considers how multiple categories of identity, difference, and disadvantage, including gender and class, interact to produce outcomes (Hyde, 2013). We identify how indigeneity intersects with cultural marginalization, landlessness, and political violence in experiences of food insecurity and highlight the unique challenges Garo women face in accessing sufficient culturally appropriate food.

\section{Methods}

The data for this manuscript were collected as part of a larger qualitative study examining gender, poverty, and chronic food insecurity among ultrapoor female heads of household in Bangladesh (McIntyre et al., 2011). The 43 women participants represented different occupational groups (urban traders, rural petty traders, garment workers, and subsistence 
agriculturalists), religious affiliations (Muslim, Hindu or Christian) and ethnic backgrounds (Bengali or Garo). The research took place between January and February 2008 in several villages in Mymensingh District near the Indian border. Using purposive sampling, with the help of a Garo community leader and a local resident who served as Garo translator, we recruited 10 Garo women based on two criteria. First, they had to be head of a household, which we defined as women who were the principal earners for households that included children or other dependents, such as elderly relatives or a disabled husband. Our criteria specified that none of the dependents should be providing significant economic support for the family. The second requirement was that the participants had to be ultrapoor - that they earned a daily income no higher than US\$1 per day.

All the participants gave informed consent by either signing their name or putting an ' $\mathrm{X}$ ' beside their name on a consent form before beginning the Daily Food Routine Interview. The language of interviews was Garo with women often interjecting comments in Bangla. Each woman was given a modest honorarium and some fruit for participating. The study was granted ethical approval by the University of Calgary/Alberta Health Services (Calgary Zone) Conjoint Ethics Board and the Bangladesh Medical Research Council.

The Daily Food Routine Interview elicits information about the day-to-day experiences of food provisioning from women, often illiterate or poor, who may be uncomfortable with being forthcoming with strangers without its stimulus (McIntyre et al., 2011). Among the conceptual underpinnings of the Daily Food Routine Interview are (a) the techniques of ethnography, which are intended to elicit knowledge about people's lives, practices, and understandings (Josephides, 2012); (b) the importance of women's lived experience, and that women are experts in their own survival; and (c) the idea of food provisioning in situations of food insecurity. The Daily Food Routine Interview permits a dialogue between the interviewer and the participant that is structured around three main questions:

1. Can you tell me about a typical day for you, from the time you get up to the time you go to bed?

2. Can you tell me about what you do on an average day to manage food and meals for yourself and your family?

3. What do you think could be done to help families such as yours provide food for themselves?

Each of the interview questions had a series of probes that addressed such topics as the woman's current family and work situation, meal planning and preparation, shopping and food acquisition, and additional food sources available or accessed (e.g., subsistence agriculture and livestock).

Interviews were conducted by L. McIntyre (Author) and a Bangladeshi interviewer trained in qualitative interview techniques, accompanied by a Garo translator, in the Mymensingh district villages of Joyramkura, Askipara, and Chorbangalia. These villages are located near the service town of Haluaghat, which is within $20 \mathrm{~km}$ of the Indian border. The interviews took place at either the participant's home or a private space agreed upon prior to the interview. Each interview was digitally recorded and typically lasted about one hour. Consistent with the practice of purposive sampling, which means that participants are recruited on the basis of particular characteristics, we continued interviewing the Garo women until we reached data saturation (i.e., additional interviews did not contribute any new information), which we did after 10 interviews (Guest, Bunce, \& Johnson, 2006). 
All of the interviews were transcribed verbatim and translated from Garo and Bangla by the Garo translator, who was fluent in both. Three English lecturers at Dhaka University, our local research counterpart from Dhaka University, and a quality-assurance translator subsequently reviewed them. This multiple review process and our attention to the details of the transcripts and translation was extremely important for validating our interview data and ensuring accuracy in our understanding of these ultrapoor Garo women's lived experiences.

Data analysis was facilitated by the use of the 2006 version of the qualitative data analysis software package NVivo, produced by QSR International, which enabled us to organize and code the data as well as to conduct systematic searches based on key ideas or themes found in our preliminary review of the data. All three authors continually revisited and closely reread the interview transcripts, double-checking for consistency in the accuracy of our findings.

Fourteen months after data collection, L. McIntyre (author) returned the findings to the Garo women at two sessions held in Askipara and Joyramkura. Four and six women respectively were in attendance (100 per cent of the original study group) and a modest honorarium was given to each woman for her participation. The Garo translator who assisted with data collection was present to conduct the translation of the meetings, from which detailed notes were recorded. The purpose of these sessions was to describe the direction of the analysis and give participants an opportunity for feedback (which was entirely affirmative), as well as ensure the validity and accuracy of our understanding of these Garo women's experiences of food insecurity and poverty. Detailed information about the larger study's methodology is presented elsewhere (McIntyre et al., 2011; McIntyre \& Munro, 2013; McIntyre \& Rondeau, 2013). As linkages emerged between indigeneity, gender, and food insecurity, the women were seen within a context of complex historical and contemporary oppressions that shaped the courses of their everyday lives.

\section{Results and Discussion}

The Garo women who participated in the study ranged in age from 30 to 55 years. Eight of the ten had no formal education. On average, they had been head of a household for about five years. Five women were supporting their disabled husbands, four had been abandoned by their husbands, and one woman was widowed. The women had, on average, four children, twice as many as the non-Garo Bengali women in our larger study with comparable inclusion criteria.

Indigenous Garo women and Bengali women shared many experiences of hardship (McIntyre et al., 2011). For example, both Garo and Bengali women described conditions of extreme food insecurity, including income deprivation, lack of employment, multiple competing basic needs, no access to government support, limited access to so-called informal supports, frequent illness, inability to afford children's schooling, and emotional distress related to the inability to provide for their families. We found profound food deprivation and an unrelenting struggle to feed their children, as well as disturbing mental anguish illustrated by reports of sleepless nights because of worry, and the desire to take poison (McIntyre \& Rondeau, 2013).

Despite such similarities, Garo experiences also diverged from those of the Bengali majority in important ways. In the following section, we show how Garo women were relegated to the most insecure, dangerous, and undesirable labour markets, resulting in serious occupational health threats. We then look at legacies of colonization, political violence, and trauma relating to displacement and marginalization, including the issue of landlessness that has plagued the Garo since the 1960s. Lastly, we show how Garo women's food insecurity is exacerbated by the demand and desire to uphold cultural traditions in trying political conditions. 


\section{Uncertain Employment and Dangerous Work}

In our study, employment was ethnically stratified, with Garo women working in occupations deemed undesirable by Bengalis. To earn money or food, Garo women worked as casual domestic workers, as agricultural labourers, or crossed the border illegally into India to collect firewood to sell.

Many Garo depend on agriculture as a means to earn money to support themselves and their families. In the early part of the twentieth century, many Garo were landowners as well as business owners. Over time, the land titles have been lost to civil unrest, displacement, and, in some cases, forced relocation. This land loss has reduced the opportunities for Garo to operate more profitable large agricultural plots and has created a large pool of seasonal agricultural labourers. Our study found that many Garo preferred agricultural work even though it was seasonal and labour intensive because it paid well compared to other types of employment opportunities available in the rural villages of Mymensingh.

Agricultural labour consisted of cultivating or sowing seeds, weeding, and harvesting crops. Women working in these jobs earned between 100 and 150 taka (\$1.40 to \$2.10 USD) per day and often received meals at work. Though it was the best income Garo women could acquire, the seasonal nature of employment created long spells of deprivation. As Sati (all names are pseudonyms), a 40-year-old woman with four children, stated:

I fall short of money in the month of May ... Then I have no work cutting paddy in the field. The price of things also rises at that time. That's why I face a shortage of food at that time.

Women said they accepted payment in advance to offset seasonal deprivation. However, wages paid in advance were significantly less than the regular wage. As a result of advance payments, women were also indebted to their employer for the next season. Garo women typically worked in people's homes as domestic labour when agricultural work was unavailable.

Domestic work was commonly available, but both Garo and Bengali women asserted this work was the absolute last resort - their "fate" when all other options failed. Domestic work was much more common among Garo women than Bengali women: six of the ten Garo participants regularly worked as domestic workers, usually for wealthier land-owning Garo families or families where remittances came from prosperous urban relatives. Similar to the Bengali women (McIntyre et al., 2011), Garo women said they disliked domestic labour because it was hard work for low wages, which might be paid in rice, and because they felt a lack of autonomy in their work. Rani, a 45-year-old mother of five with a sick husband, shared:

The payment is not so good. That's why I wish I did not have to go there. I get only one and a half a kilogram of rice after working so hard all day long. I can't tell you how bad I feel then.

To fill in gaps in income when domestic work and seasonal agricultural jobs were unavailable, Garo women illegally crossed the border into India to collect firewood that they then sold. Only Garo women attempted to earn money this way. Three of the ten women in our study collected firewood to sell in the market when there was no agricultural work available. The Indian Border Security Force (BSF) patrols the India-Bangladesh border and does not let Bangladeshis into India without a passport. As none of our participants had a passport, Garo 
women took exceptional risks by crossing the border to collect firewood. As Usha, a 50-year-old mother of four with an elderly husband, explained:

Yesterday when we went to collect firewood, they [BSF] got in our way, but still we went there. They seized our axe and chopper and also the firewood that we collected. Now I am worried thinking about how I will manage my food, how will I run my family. I can't think of any way now.

Usha, who brought her ten-year-old daughter with her to collect wood, told us, "What will we do even if we don't like it? We do it just to manage our food."

The concentration of Garo women in this undesirable and dangerous method of income generation demonstrates a form of ethnic marginalization that contributes to food insecurity. As women spoke of political violence and its ongoing effects in their families, they suggested other ways that political conditions contribute to food insecurity.

\section{Political Violence and Marginalization}

Garo women described contexts of political violence related to the ongoing struggle over land, rights, and state control in the area. Usha said that her life of "hardships" started "when the Kader Bahini [a revolutionary group formed in 1975] formed in our place." One of the West Pakistani fighters, Kader Siddiqui, recruited mainly Garo men to wage war against Bangladesh between 1975 and 1977 (Bal, 2007b). Usha explained:

I started this painful life from that time and till now I am going through that pain. This is my fate that I would run my family by collecting firewood and work in other's house. My fate has decided these difficulties for me. What will I do?

Other women described how political violence and its legacies created a burden on their families. Sati, a 40-year old woman, explained that she became the sole provider for her family after her husband was beaten by Pakistani soldiers in the 1970s.

He can't do any work because he easily becomes tired by a little hard work. Previously he used to work for an NGO ... for ten years and looked after his family. He left that job. But now he can't do any work, he doesn't even wish to do anything. Actually, his health doesn't permit him to do such hard works ... He was beaten so much. I am not sure whether it happened at the time of liberation war or at another time, I heard that my husband was beaten very badly.

Sati and others in their community said that her husband suffered trauma when he was beaten by the Pakistani soldiers, and this experience negatively impacted his mental health and prevented him from contributing to the household finances.

Political violence and exclusion may have also contributed to men's alcohol abuse and subsequent absenteeism from the family, which left women bearing the burden of earning household income on their own. Rehka, a 35-year old woman, explained that her husband's addiction and the day-to-day uncertainty it brought to her and their children was a difficult challenge: 
He goes here and there, roams around, takes food; one day he comes home if he wishes and another day he doesn't come home ... He goes here and there with other peoples like him now living in our locality.

Five of our ten Garo participants had dependent husbands living with them who each required varying degrees of caretaking because of illness or addiction. Legacies of political violence were apparently widespread in Garo communities and persisted in social forms that affected household food and income. Garo women identified the loss of their traditional lands as a legacy of political violence and marginalization that rendered them almost solely dependent on working for income to purchase food.

\section{Loss of Traditional Lands}

Garo women indicated a deep attachment to the land on which they lived and viewed it as an asset passed down from generations of women, a source of sustenance and provision, and, in terms of resistance politics, as "Garo Lands" or the "imagined homeland" of their people. Throughout the interviews and in the returning-results sessions, many of the Garo women spoke about the land that surrounded their houses, which once belonged to their families but was now in the possession of Bengali migrants. Some women's parents had sold the land, which often contained ponds used for aquaculture, rather than be driven out empty-handed. In the returningresults session held in Askipara, other properties were said to have been taken by force by "cunning land grabbers."

Landlessness impacted women's ability to grow food. Lili, a 50-year-old widow with one son said, 'I have no land. How can I make a garden here? I only have the house where I live and the yard; that's all.' The problem Lili described was common among the ten Garo women in our sample. Seven of them said they owned their own house, but they had little or no surrounding land they could use to produce food.

Some Garo women practised a very minimal level of subsistence agriculture by raising ducks and chickens, and pigs if they could afford to do so. Women stated that they were proud of what little they could provide for themselves through gardens and domesticated animals, and asserted that they would use any extra income to develop their land and its productivity.

Landlessness not only affected the ability to produce food and generate agricultural income, but also created overcrowded housing conditions and strained household resources as women tried to provide for large Garo families. Adherence to Christian teachings discouraged the use of birth control. Lili said, 'We don't have enough place to build house to live, how canwe make a pond? We, five families, are living in this place very densely'. Similarly, Rekha identified landlessness as a major source of hardship for her and her children:

People face much difficulties rearing up three or four children while I am rearing up my nine children alone. You see how I am doing that! If they [women like herself] had been given land they could cultivate that to maintain their family somehow.

\section{Efforts to Uphold Cultural Identity}

The issue of land dispossession extended into the state's cultural marginalization of Garo Christians, exemplified by hearsay reports that a Garo woman had donated land for a school, but the state had created an Islamic public school there attended only by Bengali children. Garo families were then forced to pay the extra cost of sending their children to a private Christian 
school to maintain cultural identity. Indeed, the struggle to keep Garo traditions and identity alive was clearly evident in the women's reports of their concerns over food, schooling and land.

As heads of households, ultrapoor Garo women said they were responsible for ensuring that their children had enough to eat, attended school to receive an education, and learned "Garo ways." All of the women's narratives focused on the overwhelming personal "worries" and "tension" they experienced when thinking about how to manage their maternal and cultural responsibilities in conditions of profound poverty (McIntyre \& Rondeau, 2013). Dipika, a 30year-old woman who had been abandoned by her husband and was raising five children shared,

What I think ... how I will bring up my kids? How will I give them food? These are my worries. I can't make them study ... I can't give them clothes ... I feel bad about it. How will I feel good? I feel so bad.

A Christian education was regarded among the respondents as a requirement for preserving cultural identity among Garo children, yet all the Garo women in our study indicated that this necessity was one they had had to forgo due to food insecurity. Similar frustrations were described with regard to maintaining matrilineal kinship practices.

Matrilineal kinship has culturally defined the Garo for many centuries (Bal, 2007b). Matrilineal lineage is significant for inheritance. Traditionally, property was passed from mother to daughter; however, due to land dispossession, this practice has declined. As a result, a number of Garo women in our study were not able to live in their natal homes and properties, and resided instead with their husband's relatives. Other women, who were able to live in their mother's home, did not have property rights. There was a strong concern among the women that they did not have land to pass on to their daughters, creating intergenerational threats to food security. As Rajana said, "Now my daughters have their own family. They can't give me anything also. They are running their own family along with their kids. They have no land-property."

Women described their need to meet cultural expectations concerning family continuity by securing a marriage for their daughters. Rekha shared that she had had to borrow money at a high interest rate to entertain eligible suitors for her daughter during the Christmas holidays. Although a significant debt was acquired, she was pleased that a marriage arrangement had been settled for her daughter. Similarly, Vijaya, a 40-year-old woman with five children who was abandoned by her husband, had borrowed 6,000 taka (about \$86 USD) from a Bengali moneylender to repay an outstanding loan. She used some of the money to buy ducks and chickens that would generate income, but then cooked them during Garo ceremonies:

Because, in our tradition, we have to bring rice, pulse, ducks, chickens, onion, and chilies on the occasions like wedding ceremony and funeral. So, I had to do it and in this way, I lost my ducks and chickens. In this way I spent all my 6,000 taka. I have to pay the instalment of 160 taka per week for that loan now.

Women expressed concern over how to maintain other land- and food-based traditions given limited resources and almost daily food shortages. Pig feasts were typically held at Garo weddings and funerals and at Christmas and New Year's celebrations. Urban Garo who returned home with the expectation of a traditional feast attended holiday celebrations in the village, but special foods of any kind, let alone pigs, were beyond the reach of the Garo women in our study.

Mitali, an old woman with two grown children who was living in the house she inherited from her parents revealed that she and other women had considered leaving home to look for 
work as "many people from this village go to Dhaka." Mitali contemplated this option and reflected on her ties to her rural residence:

There are people like me. We share our sorrows among ourselves. But when we are happy we work with happiness. If we could go outside, like Dhaka, to do some work, as some other people do, it would be helpful to bring up our children. But we can't do that [leave].

Mitali voiced a sentiment also expressed by many of the other women; that connection to their lands and extended families was too important to sever, outweighing the expected benefits of urban migration. This suggests the need for more research into the trend observed by Geharz (2010) and Bal (2007b) towards increased Garo urban migration and upward mobility. Similarly, although the Garo women's aspiration to stay in their homeland aligns well with the symbolic values of cultural identity and indigeneity promoted by the Indigenous rights and food sovereignty movements, full consideration must also be given to the real-world hardships they face at home. The gendered imperative of maintaining Garo traditions in the context of land dispossession, urban migration, and pressures from the state to conform to Bengali cultural values appears to exacerbate food insecurity.

\section{Conclusions: Gender, Indigeneity and Food Insecurity}

Garo women's experiences indicate the need for more attention to past and present political conditions, including state practices and Indigenous struggles for political recognition and cultural identity, as these shape food insecurity among Indigenous women. Compared to non-Garo Bengali women in the study, Garo women were overrepresented in irregular, dangerous and otherwise undesirable fields of work such as domestic labour or crossing the Indian border in search of firewood to sell. This was epitomized when women said their preferred occupation was seasonal agricultural labour, despite the fact that it left them deprived of income as well as indentured and indebted to their employers. As a result of the political denial of Indigenous rights by the Bangladeshi state, Garo women found themselves in the position of almost single-handedly trying to uphold aspects of cultural identity such as Christian education, matrilineal inheritance and marital practices, and special foods and celebrations. Above all, without access to their mothers' lands, Garo women experienced physical, cultural, and emotional trauma that could not be reduced solely to the fact that they could not grow vegetables, steward a pond, or raise domesticated animals. Similar to Power's (2008) argument that, "for some aboriginal people, the ability to access sufficient and safe traditional/country food, or food security, is integral to cultural health and survival" (p. 96). For the Garo, political and cultural rights to land and identity are essential to achieving food security and other basic needs.

Our analysis complements feminist and Indigenous studies scholarship that locates women at the intersection of often competing notions of class, culture, ethnicity, and gender (Mohanty, 1988; Radcliffe \& Pequeño, 2010; Yuval-Davis \& Anthias, 1989). The example of Garo women builds on seminal work by Barndt (1999, 2008), who, through a feminist intersectional analysis of Mexican Indigenous women, demonstrates the complex ways that overlapping ethnic, gender, age, and rural or urban identities interact with the micropolitics of work, and the impact these overlapping identities have on accessing traditional foods and food security. In particular, our research provides insight into the importance of historical, political, 
and economic specifics in understanding the micropolitics of food insecurity. Socioeconomic determinants of food insecurity are not enough to explain Indigenous women's exclusion at the axis of politics, gender, and indigeneity. Legacies of cultural trauma, landlessness, political violence, substance abuse, and mental health problems clearly affect women's ability to generate income and sustain their families. Similarly, food insecurity may be exacerbated by the politics of culture as Indigenous movements struggle for rights and food sovereignty in national political contexts. In the Garo case, rural Indigenous women's interests are served neither by the government that wishes to erase cultural differences nor by the opposition movements that publicly identify women as keepers of tradition, but give insufficient attention to the poverty and limiting conditions under which women must try to meet those expectations. To begin to disentangle the linkages of indigeneity, gender, and food insecurity, ultrapoor Garo women are in need of poverty alleviation from not only Indigenous organizations who market their cultural capital but also from governmental and non-governmental aid and development programs that already offer such assistance to vulnerable Bengali women. Discussions with the Bangladesh Indigenous Peoples' Forum that followed the returning-results sessions of this study suggest that there is receptivity to this recommendation (private stakeholder meeting, March 19, 2009). We have similarly discussed and documented, for both mainstream non-governmental organizations (e.g., BRAC) and the Government of Bangladesh, which administers social safety net programmes (e.g., food assistance, infrastructure-building, job training, education, disaster relief) for disadvantaged groups, that the particular conditions experienced by Garo women may not be adequately addressed by their activities (private stakeholder meetings, March 2009); McIntyre et al, 2011; McIntyre \& Munro, 2013). Further progress to this end will require both indigenous rights-based advocacy and inclusive poverty reduction strategies.

\section{References}

Atkinson, J. (2002). Trauma trails, recreating song lines: The transgenerational effects of trauma in indigenous Australia. North Melbourne, AU: Spinifex.

Bal, E. (2007a). They ask if we eat frogs: Garo ethnicity in Bangladesh. Singapore: Institute of Southeast Asian Studies.

Bal, E. (2007b). Becoming the Garos of Bangladesh: Policies of exclusion and the ethnicisation of a "tribal" minority. Journal of South Asian Studies, 30, 439-55. doi:10.1080/00856400701714062

Barndt, D. (1999). Fruits of injustice: Women in the post NAFTA food system. Canadian Women's Studies/Les Cahiers de la Femme, 21, 82-88.

Barndt, D. (2008). Tangled routes: Women, work, globalization and the Tomato Trail. (2nd ed.). Maryland, US: Rowman \& Littlefield Publishers.

Beaumier, M. C. \& Ford, J. D. (2010). Food insecurity among Inuit women exacerbated by socio-economic stresses and climate change. Canadian Journal of Public Health, 101, 196-201. 
Garo Food Insecurity • Jenny Munro, Barbara Parker, Lynn McIntyre

Bourassa, C., McKay-McNabb, K., \& Hampton, M. (2005). Racism, sexism, and colonialism: The impact on the health of Aboriginal women in Canada. Canadian Woman Studies, 24, 23-29.

Cannon, M. J. \& Sunseri, L. (2011). Racism, colonialism and indigeneity in Canada. Oxford, UK: Oxford University Press.

Chilton, M. \& Booth, S. (2007). Hunger of the body and hunger of the mind: African American women's perceptions of food insecurity, health and violence. Journal of Nutrition Education and Behavior, 39, 116-25. doi:10.1016/j.jneb.2006.11.005

Das, T. K. \& Islam, H. Z. (2005). Psycho-social dimensions of ethnicity: The situation of Garo community in Bangladesh. Asian Affairs, 27(3), 45-54.

Desmarais, A. A. (2003). The Via Campesina: Peasant women on the frontiers of food sovereignty. Canadian Women Studies/Les Cahiers de la Femme, 23, 140-145.

Devendra, C., \& Chantalakhana, C. (2002). Animals, poor people and food insecurity: Opportunities for improved livelihoods through efficient natural resource management. Outlook on Agriculture, 31, 161-175. doi:10.5367/000000002101294010

Gerharz, E. (2010). Approaching indigenous activism from the ground: Experiences from Bangladesh. In T. Faist (Ed.), Working papers (p. 74). Bielefeld, DE: Center on Migration, Citizenship and Development.

Guest, G., Bunce, A., \& Johnson, L. (2006). How many interviews are enough? An experiment with data saturation and variability. Field Methods, 18, 59-82.

doi: $10.1177 / 1525822 \times 05279903$

Haddad, S., Mohindra, K. S., Siekmans, K., Màk, G., \& Narayana, D. (2012). "Health divide" between indigenous and non-indigenous populations in Kerala, India: Population based study. BMC Public Health, 12, 390. doi:10.1186/1471-2458-12-390

Hamilton, W. L., Cook, J. T., Thompson, W. W., Buron, L., Frongillo, E., \& Olson, C. (1997). Household food security in the United States in 1995: Summary report of the Food Security Measurement Project. Washington, DC: United States Department of Agriculture, Food and Consumer Service.

Hughes, R. G. \& Lawrence, M. (2005). Globalisation, food and health in Pacific Island countries. Asia Pacific Journal of Clinical Nutrition, 14, 298-306.

Hyde, J. S. (2013). Gender similarities and differences. Annual Review of Psychology. [Epub ahead of print]. doi:10.1146/annurev-psych-010213-115057

Josephides, L. (2012). Finding and mining the talk: Negotiating knowledge and knowledge transfer in the field. In J. Skinner (Ed.), The interview: An ethnographic approach (pp. 89-104). London, UK \& New York, US: Berg. doi:10.5040/9781474214230.ch-003 
Kuhnlein, H. V., Erasmus, B., \& Spigelski, D. (Eds). (2009). Indigenous Peoples food systems: The many dimensions of culture, diversity and environment for nutrition and health. Rome, IT: Food and Agriculture Organization of the United Nations.

McIntyre, L. \& Munro, J. (2013). "Nobody helps us": Insights from ultrapoor Bangladeshi women on being beyond reach. Development in Practice, 23, 157-168. doi:10.1080/09614524.2013.772118

McIntyre, L., Rondeau, K., Kirkpatrick, S. I., Hatfield, J., Islam, K. S., \& Huda, S. N. (2011). Food provisioning experiences of ultrapoor female heads of household living in Bangladesh. Social Science and Medicine, 72, 969-976. doi:10.1016/j.socscimed.2011.01.011

McIntyre, L., \& Rondeau, K. (2013). Understanding the aspirations of ultra poor women in Bangladesh can enhance wellbeing and target development efforts. International Journal of Wellbeing, 3, 82-97. doi:10.5502/ijw.v3i1.5

Mohanty, C. T. (1998). Under Western eyes: Feminist scholarship and colonial discourse. Feminist Review, 30, 60-88. doi:10.2307/1395054

Orticio, G. (2006). Indigenous knowledge and IP food security: A review of concepts and cases. Available from http://eprints.qut.edu.au/62094/1/ORTICIO,_GINO_Indigenous_Knowledge_and_IP_Fo od_Security_A_Review_of_Concepts_and_Cases.pdf

Patel, R., Balakrishnan, R., \& Narayan, U. (2007). Transgressing rights: La Via Campesina's call for food sovereignty / exploring collaborations: Heterodox economics and an economic social rights framework / workers in the informal sector: Special challenges for economic human rights. Feminist Economics, 13, 87-116. doi:10.1080/13545700601086838

Power, E. M. (2008). Conceptualizing food security for Aboriginal people in Canada. Canadian Journal of Public Health, 99, 95-97.

Price, J. \& Asgary, R. (2011). Women's health disparities in Honduras: Indicators and determinants. Journal of Women's Health, 20, 1931-1937. doi:10.1089/jwh.2010.2615

Public Health Agency of Canada. (2008). The Chief Public Health Officer's report on the state of public health in Canada 2008. [Cat.: HP2-10/2008E]. Ottawa, ON: Minister of Health.

Radcliffe, S. \& Pequeño, A. (2010). Ethnicity, development and gender: Ts'achila indigenous women in Ecuador. Development and Change, 41, 983-1016. doi:10.1111/j.14677660.2010.01671.x

Shiva, V. (2000). Stolen harvest: The hijacking of the global food supply. Cambridge, MA: South End Press. 
Spieldoch, A. (2007). A row to hoe: The gender impact of trade liberalization on our food system, agricultural markets and women's human rights. Geneva, $\mathrm{CH}$ : Friedrich-EbertStiftun.

Uddin, M. K. (July 2008). Rights and demands of the Indigenous People: Perspective from Bangladesh. Paper presented at the International Peace Research Association conference, University of Leuven, Leuven, BE.

Wittman, H., Desmarais, A., \& Wiebe, N. (2011). The origins and potential of food sovereignty. In H. Wittman, A. Desmarais, \& N. Wiebe (Eds), Food sovereignty in Canada: Creating just and sustainable food systems (pp. 1-14). Halifax, NS \&Winnipeg, MB: Fernwood Publishing.

Yuval-Davis, N. and Anthias, F. (1989). Woman-Nation-State. London, UK: Macmillan. doi:10.1007/978-1-349-19865-8 